\title{
Desain dan Realisasi Pemrosesan Citra dengan CMUcam4 untuk Meningkatkan Kinerja Visual Robosoccer
}

\author{
Asep Najmurrokhman*), Kusnandar, Bambang HSR Wibowo, Syurya Abiddin \\ Jurusan Teknik Elektro, Fakultas Teknik \\ Universitas Jenderal Achmad Yani \\ Jl. Terusan Jendr. Sudirman PO Box 148 Cimahi 40533 \\ *) email : asepnajmu@yahoo.com
}

\begin{abstract}
Abstrak-Robot sepakbola (robosoccer) adalah sebuah robot humanoid yang dirancang agar dapat bermain sepak bola seperti layaknya tim sepakbola manusia. Kemampuan yang dimiliki oleh sebuah robosoccer adalah identifikasi terhadap bola, pemain dalam satu tim, pemain lawan, dan gawang. Makalah ini memaparkan tentang desain dan realisasi pemrosesan citra bola, garis, dan gawang untuk meningkatkan kemampuan visual sebuah robot sepakbola (robosoccer). Metode penelitiannya mencakup pelacakan warna dengan menggunakan sensor kamera CMUcam4 yang sudah dilengkapi dengan pemroses citra digitalnya. Pelacakan warna adalah kemampuan untuk mengambil suatu gambar, mengisolasi warna tertentu, dan mengekstrak informasi tentang lokasi suatu daerah gambar yang berisi warna tertentu. Untuk menentukan warna tersebut, diperlukan nilai minimum dan nilai maksimum untuk tiga kanal warna. Setiap warna yang unik dihasilkan melalui proses pencampuran nilai merah, hijau dan biru (RGB) dengan komposisi tertentu. Hasil pengujian menunjukkan bahwa penerapan pengolah citra CMUcam4 dalam aplilasi robosoccer dapat meningkatkan kinerja visual robosoccer dalam mengenali bentuk dan warna bola, gawang, dan tepi garis lapangan.
\end{abstract}

Kata kunci-robosoccer; pelacakan warna; RGB; CMUCam4.

\section{Pendahuluan}

Robot sepakbola adalah sekumpulan robot humanoid yang bekerja sama menghasilkan gol ke gawang lawan [1]. Menurut FIRA (federation of international robosoccer association) sebagai organisasi yang mengembangkan robot sepakbola, penelitian terkait dengan robot sepakbola mencakup penelitian tentang koordinasi antar bagian dalam satu tim yang masingmasing anggotanya disebut agen, sehingga tim robot sepakbola disebut multi agent [2]. Setiap agen memiliki dinamika dan karakteristik spesifik tetapi secara keseluruhan tim tersebut harus berkoordinasi mencapai tujuan yang diinginkan. Kemampuan yang dimiliki oleh sebuah robosoccer adalah identifikasi terhadap bola, pemain dalam satu tim, pemain lawan, dan gawang. Kemampuan tersebut harus ditunjang oleh kinerja visual robosoccer dalam mengenali objek yang ada di sekelilingnya. Beberapa peneliti telah melaporkan tentang strategi dan algoritma dalam mengenali objek bola dalam aplikasi robosoccer [3-6]. Zhang dkk. dalam [3] menjelaskan tentang algoritma pengenalan bola berbasis pandangan ke segala arah dengan menggabungkan metode pengenalan citra tertentu dan metode komputasi AdaBoost untuk pengklasifikasi datanya. Rahman dan Widodo dalam [4] menguraikan tentang metode pelacakan posisi bola berwarna dengan kamera kecil yang terpasang pada robot kemudian menerapkan penapisan (filtering) warna berdasarkan model warna HSL (Hue-Saturation-Lightness) untuk setiap frame dalam gambar video. Lu dkk. dalam [5] mendeskripsikan tentang metode pengenalan bola tanpa klasifikasi warna bola. Hwang dkk. dalam [6] memaparkan metode pengenalan bola dan gawang sebuah robosoccer dengan teknik jaringan syaraf artifisial dan strategi navigasi visualnya. Dalam konteks penggunaan sensor untuk mendukung kinerja visual robot, Bečanović dkk. dalam [7] memperkenalkan sensor optik neuromorphic yang disusun oleh rangkaian terpadu tipe VLSI (very large scale integration) dengan kemampuan komputasi gerak dan estimasi posisi spasial objek yang bergerak. Sementara itu, Dodds dkk. dalam [8] mengusulkan metodologi benchmarking dan ukuran kinerja untuk sistem visual robosoccer.

Berkaitan dengan pengenalan objek, ada dua pendekatan yang dilakukan dalam mengenali benda di sekeliling robosoccer, yaitu melibatkan warna $[4,6]$ atau tanpa klasifikasi warna [5, 9]. Dalam hal tanpa klasifikasi warna, robosoccer hanya mengenali bentuk dan harus mampu membedakan bentuk benda di sekelilingnya. Dalam makalah ini, pengenalan objek benda yang harus dikenali oleh robosoccer melibatkan warna dari benda tersebut. Objek tersebut ditangkap oleh sensor kamera yang terpasang di kepala robot dan citranya diolah melalui prosesor citra CMUcam. Penggunaan prosesor citra CMUcam dalam kompetisi robotika sudah dimulai sejak tahun 2008 [10]. Dewasa ini, CMUcam menjadi komponen standar dalam aplikasi-aplikasi yang membutuhkan sensor visual yang kecil, kompak, berdaya rendah, dan cerdas [11]. Disamping memiliki keunggulan dalam spesifikasi teknisnya, perangkat lunak yang bersifat open source untuk menjalankan fungi 
CMUcam menjadi daya tarik bagi peneliti dalam menerapkan sensor visual sebagai komponen utama dalam navigasi sistemnya.

\section{PERANCANGAN SISTEM}

Diagram blok sistem robosoccer yang dibangun dalam penelitian diperlihatkan dalam Gambar 1. Sistem tersebut terdiri atas sebuah pengendali utama berupa mikrokontroler Arduino Uno, mikrokontroler CM-510 sebagai pengendali motor servo untuk menggerakkan robot, sensor kompas sebagai pemandu navigasi robot, dan sensor kamera yang digerakkan oleh motor servo. Sensor kamera yang terpasang pada robot tersebut merupakan pemandu visual robot dalam mengenali objek yang ada di sekelilingnya.

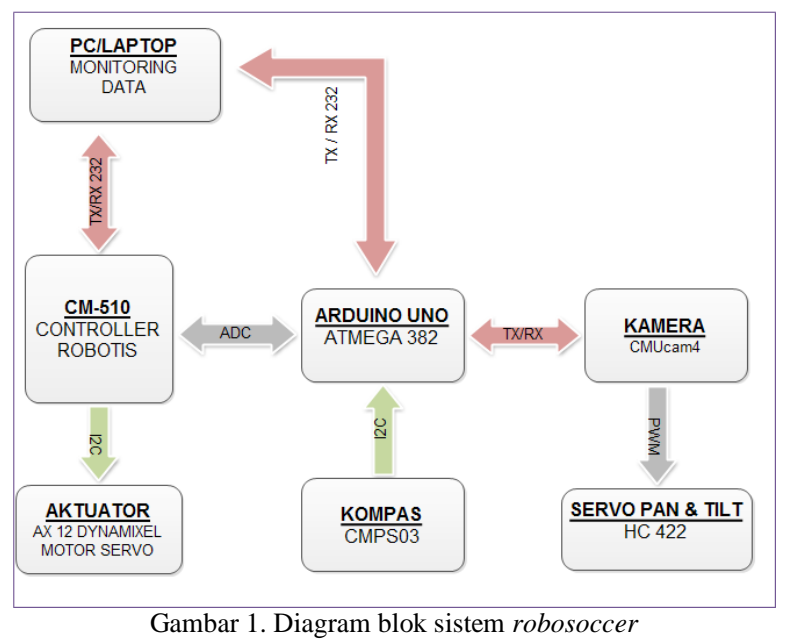

Dalam penelitian ini, sebuah modul sensor elektronis yang sudah dilengkapi dengan prosesor pengolah citra dipasang untuk meningkatkan kinerja visual robosoccer. Modul sensor yang digunakan tersebut disebut sebagai CMUcam. CMUcam terdiri dari kamera kecil dan mikrokontroler dengan antarmuka serial. Antarmuka yang ringan pada CMUcam memungkinkan untuk dapat diprogram oleh mikrokontroler, Dalam penelitian ini, seri CMUcam yang digunakan bertipe CMUcam4. Versi tersebut memiliki modul kamera yang dapat digunakan untuk berbagai macam aplikasi dan mampu dihubungkan dengan kontroler utama, seperti PC atau Arduino(AVR). Berbasiskan prosesor utama Parallax P8X32A yang merupakan propeller chip dimana terdapat 8 buah prosesor di dalam chip tersebut, modul kamera ini mampu mengakomodasi pengolahan gambar digital dengan cepat dan data tersebut dapat dibaca dengan mudah oleh mikrokontroler, seperti Arduino Uno. Bentuk fisik CMUcam4 diperlihatkan dalam Gambar 2. Selain memiliki prosesor utama yang cukup tinggi spesifikasinya, CMUcam4 juga menggunakan sensor kamera CMOS OV9665 1.3 MegaPixel yang telah dilengkapi dengan lensa kamera dengan ukuran yang lebih kecil jika dibandingkan dengan CMUcam versi sebelumnya. Selain perbaikan dari sisi fitur dari pengolahan gambar digital, CMUcam4 juga menyediakan tambahan fitur TV-Out yang mampu menampilkan gambar di TV.
Konfigurasi yang paling umum untuk CMUcam4 adalah untuk berkomunikasi dengan prosesor utama yaitu melalui port serial TTL menggunakan port TX RX pada komputer (melalui USB atau RS232), Arduino, Basic Stamp, PIC, atau mikrokontroler yang sama. CMUcam4 cukup sederhana untuk embedded system yang tidak memerlukan komputer untuk memprogramnya karena prosesor utama CMUcam4 ini telah diisi dengan program untuk membaca dan melacak gambar. Pada CMUcam4 juga terdapat beberapa protocol atau command untuk mengendalikan kamera tanpa di koneksikan dengan komputer cukup dengan mikrokontroler sebagai pengendali pengganti komputer.

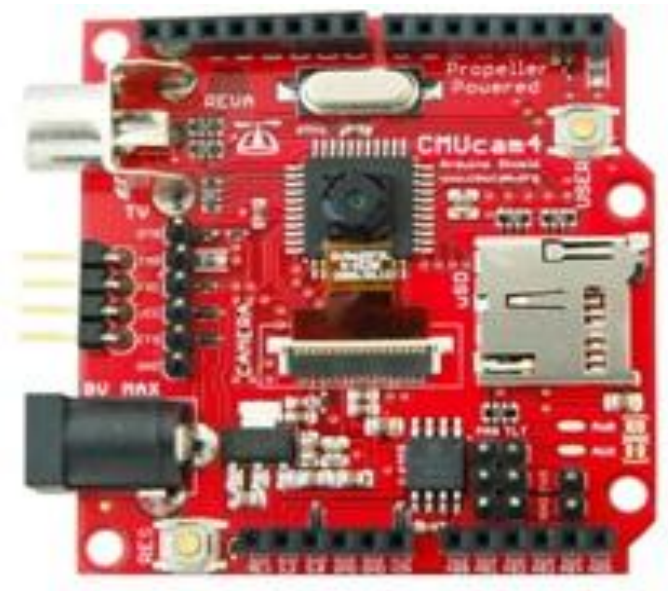

Gambar 2. Board CMUcam4 [11]

Untuk mengoperasikan CMUcam4, sebuah perangkat lunak yang disebut dengan CMUcam4GUI telah dibangun untuk mengoperasikan kamera CMUcam4. CMUcam4GUI dapat mengambil gambar dan ditampilkan pada monitor komputer. Gambar yang akan dilacak tersebut dapat diberi kotak untuk dapat dihitung lebar pikselnya dan dapat diberi batas-batas pelacakannya. Dengan menggunakan CMUcam4GUI, batas pelacakan warna untuk sebuah objek dapat ditentukan dengan cepat dalam satu adegan pencahayaan dan memperluas batas pelacakan warna untuk mendukung pelacakan objek dalam mengubah adegan pencahayaannya. CMUcam4GUI juga memungkinkan untuk melihat apa yang dilacak dengan CMUcam4 secara real time tanpa TV dengan menampilkan isi dari pelacakan berupa histogram dan bingkai grafis yang dikirim oleh CMUcam4. Tampilan CMUcam4GUI diperlihatkan pada Gambar 3. 


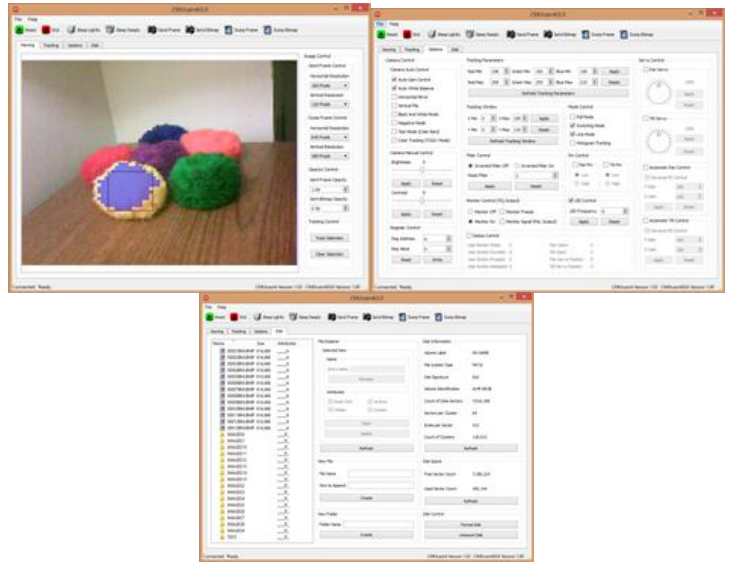

Gambar 3. Tampilan CMUcam4GUI.

\section{A. Metoda Pelacakan Warna dengan Kamera CMUcam4} [12]

Pelacakan warna adalah kemampuan untuk mengambil suatu gambar, mengisolasi warna tertentu, dan mengekstrak informasi tentang lokasi suatu daerah gambar yang berisi warna tertentu. Untuk menentukan warna tersebut, diperlukan nilai minimum dan nilai maksimum untuk tiga kanal warna. Setiap warna yang unik diwakili oleh nilai merah, hijau dan biru (RGB) yang mengindikasikan berapa banyak setiap warna pada kanal tersebut dicampur. Pada CMUcam4, setiap kanal warna tersebut memiliki batasan nilai dari 0 (nol) sampai 255 sehingga diperlukan enam nilai yang merepresentasikan nilai minimum dan maksimum setiap kanal warna yang ingin dilacak. Setelah ditentukan, CMUcam4 mengambil nilai tersebut dan memulai untuk memproses gambar. Banyak metoda yang dapat dipakai untuk melacak warna, CMUcam4 mengambil metoda yang sederhana yaitu memproses setiap frame gambar dari kamera secara terpisah. Dimulai dari bagian atas kiri gambar dan secara berurutan meneliti setiap piksel baris demi baris. Jika piksel tersebut memenuhi nilai warna yang ingin dilacak maka posisi tersebut ditandai. Nilainilai tersebut kemudian digunakan untuk mengetahui posisi kiri atas, kiri bawah, kanan atas dan kanan bawah dari warna yang terlacak pada gambar sehingga terbentuk kotak yang melingkupi warna yang diinginkan tersebut. Pada akhir gambar, CMUcam4 menjumlahkan nilai piksel yang terdapat pada kotak tersebut dan mencari titik tengah dari kotak tersebut. Oleh karena itu, informasi yang dikeluarkan dalam pelacakan warna pada CMUcam4 berupa posisi $\mathrm{x}$ awal, $\mathrm{y}$ awal, $\mathrm{x}$ akhir, $\mathrm{y}$ akhir, titik tengah $\mathrm{x}$, titik tengah $\mathrm{y}$, dan jumlah piksel seperti yang diperlihatkan dalam Gambar 4 .

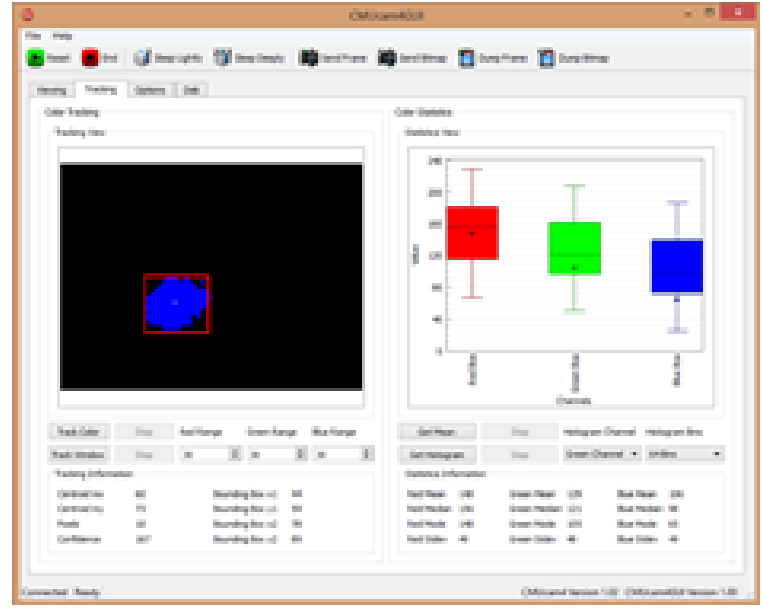

Gambar 4. Pelacakan warna

\section{B. 2.2 Diagram alir proses pelacakan warna oleh CMUcam4}

Diagram alir umum proses pelacakan warna oleh CMUcam4 untuk aplikasi robosoccer diberikan dalam Gambar 5. Dalam diagram alir tersebut, kamera CMUcam4 akan berfungsi apabila diberi perintah untuk melakukan pelacakan warna dengan menggunakan kedua servo yang terhubung pada kamera dan diberi perintah oleh mikrokontroler Arduino sebagai komponen pemroses utama dalam sistem. Dalam proses pelacakan ini kamera akan selalu mengarah pada titik setpoint pada jendela kamera CMUcam4 yaitu pada koordinat $[\mathrm{x}, \mathrm{y}]=[100,11]$ sesuai dengan piksel benda yang dilacak untuk gawang dan $[\mathrm{x}, \mathrm{y}]=[75,75]$ pada bola. Jika kamera tidak mendapatkan titik koordinat tersebut maka kamera akan melakukan scanning sampai mendekati setpoint koordinat benda. Pada bagian pengontrol utama Arduino Uno, robot pertama kali dioperasikan dalam keadaan standby dengan nilai data pada sensor dalam keadaan 0 atau belum ada kondisi apapun. Ketika "sound $=1$ " maka robot akan mulai bergerak melacak mencari bola warna orange sesuai dengan keadaan pada kuadran kamera. Apabila bola tidak terdeteksi maka kamera akan mengambil data dari Arduino dengan nilai parameter RGB 255,73,139. Setelah kamera menemukan setpoint maka robot akan berjalan mendekati bola. Jika bola sudah mulai dekat dengan nilai "koordinat $X !=0||$ koordinat $Y !=0$ dan $x$ Gawang $=$ nilai Servo $x "$, maka robot akan mulai melacak warna gawang kuning dengan nilai parameter RGB 226,229,149. Apabila warna gawang tidak terlacak maka kamera akan mengambil data dari Arduino dengan data tersebut. Setelah menemukan gawang, robot akan menentukan arah menendang bola yang searah dengan gawang sehingga nilai parameternya tertentu. 


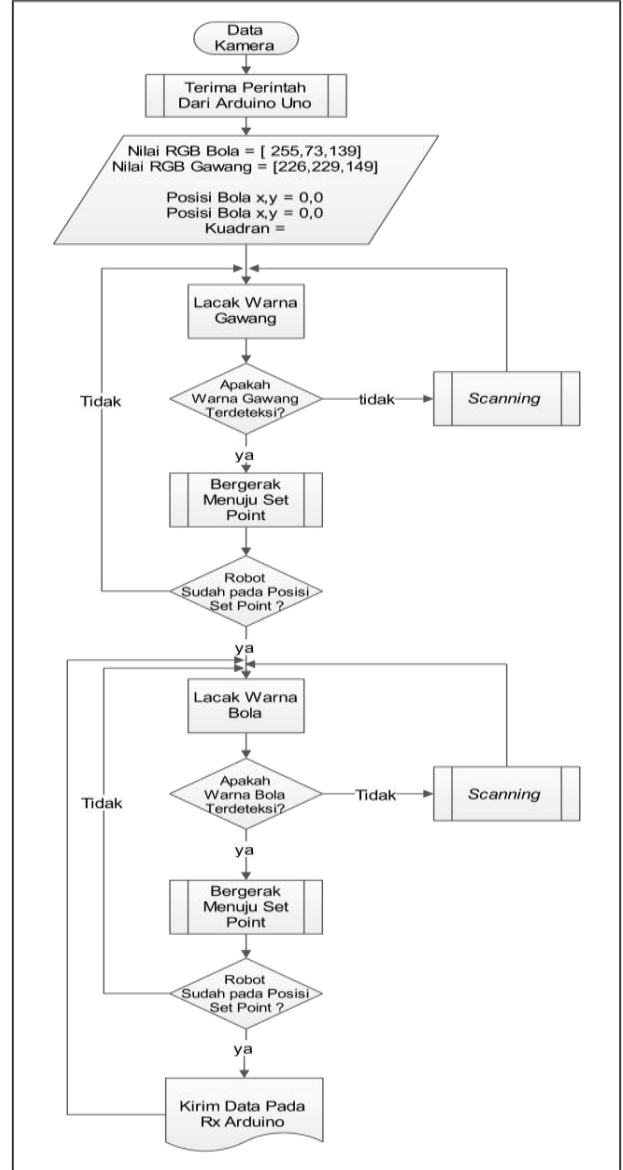

Gambar 5. Sub Proses Diagram Alir Pelacakan Warna oleh CMUcam4.

\section{HASIL PENGUJIAN DAN DISKUSI}

Proses deteksi objek dengan sensor kamera CMUcam4 menggunakan CMUcam4GUI melalui beberapa tahap yaitu pengambilan gambar benda yang akan dilacak dengan CMUcam4GUI, pemolaan gambar yang dilacak dengan CMUcam4GUI, dan pengambilan parameter nilai RGB dari hasil pemolaan dengan CMUcam4GUI tersebut. Proses pemolaan pada bola dan pengambilan sampel model untuk dapat dilacak oleh kamera CMUcam4 dilakukan agar kamera dapat mengenali dimensi bola dan warna bola dengan cara mengetahui jumlah piksel pada gambar yang diambil oleh kamera CMUcam4 dan dapat mengetahui nilai RGB pada bola tersebut. Pengambilan sampel bolanya diperlihatkan pada Gambar 6.

Pengambilan model gambar dilakukan dengan memotret frame pada jendela CMUcam4 lalu memberi tanda kotak pada model bola yang akan dilacak seperti diperlihatkan pada Gambar 7. Dalam penelitian ini, sampel bola berwarna oranye sesuai dengan warna bola yang harus dideteksi oleh robosoccer yang digunakan.
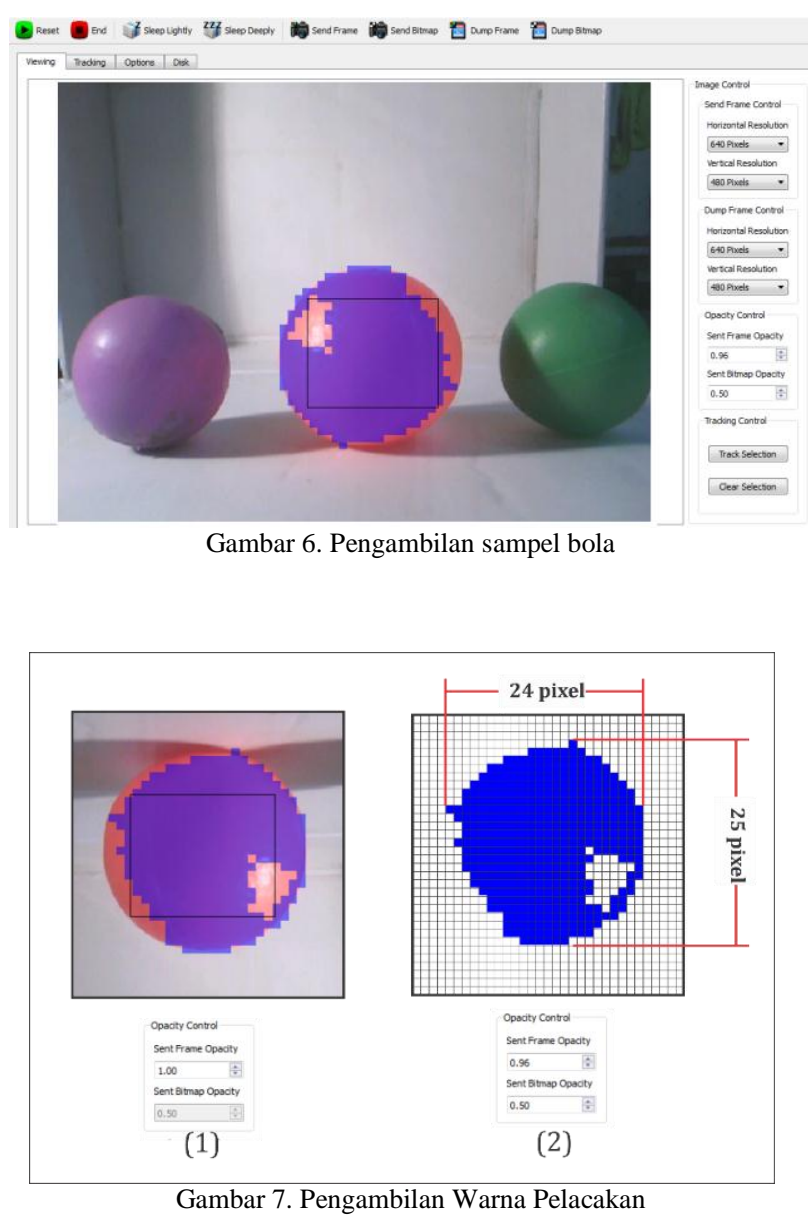

Tahap selanjutnya yaitu pemberian tanda dengan mengatur opacity control pada GUI dalam Gambar 7(1). Pada bagian opacity control terdapat dua bagian pengaturan frame dan bitmap opacity, masing - masing nilai dari bagian tersebut di perkecil menjadi 0,96 dan 0,50 agar sampel model lebih jelas seperti pada Gambar 7(2), sehingga pada saat pelacakan bola kamera dapat melacak bola dengan baik. Dari pengaturan tersebut, nilai parameter RGB untuk bola diperlihatkan pada Gambar 8.

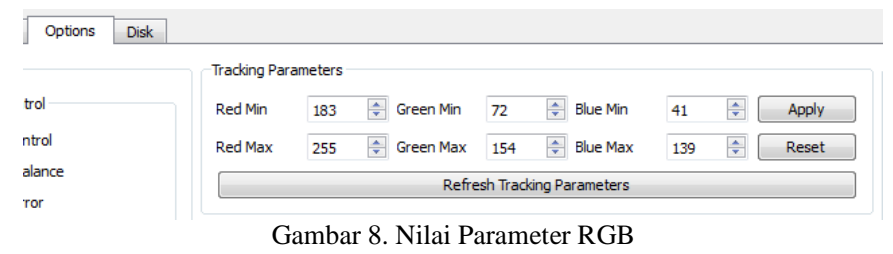

Dari proses tersebut, kamera akan memberikan nilai parameter RGB kepada prosesor digital dalam CMUcam4 dan selanjutnya nilai parameter tersebut diberikan dalam inisialisasi program mikrokontroler Arduino Uno sebagai pengendali utama dalam sistem robosoccer ini.

Objek berikutnya yang harus dikenali oleh robosoccer adalah gawang dan garis tepi lapang. Dalam hal ini, sampel yang akan diolah oleh CMUcam4 berupa informasi warna dari 
gawang dan garis tepi tersebut, seperti diberikan dalam Gambar 9.

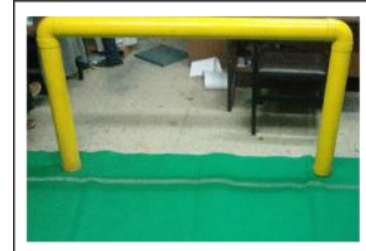

(1)

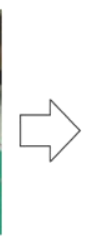

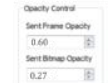

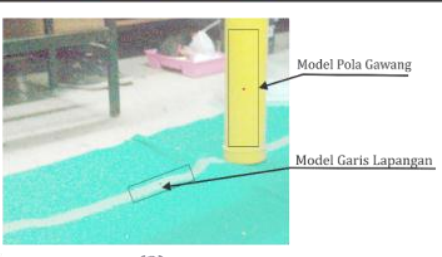

(2)
Gambar 9. (1) Gambar Gawang dan Tepi Garis; (2) Citra yang diolah oleh CMUcam4.

Gambar 9(1) memperlihatkan citra asli sedangkan Gambar 9(2) adalah citra yang diolah dengan opacity control pada GUI kamera ditentukan frame opacity dan bitmap opacity masing masing bernilai 0,60 dan 0,27. Nilai tersebut diberikan agar kamera mudah fokus dalam pelacakan warna dan tidak mudah lost tracking. Dari hasil pengaturan nilai tersebut, nilai RGB untuk gawang dan garis tepi lapang diperlihatkan pada Gambar 10.

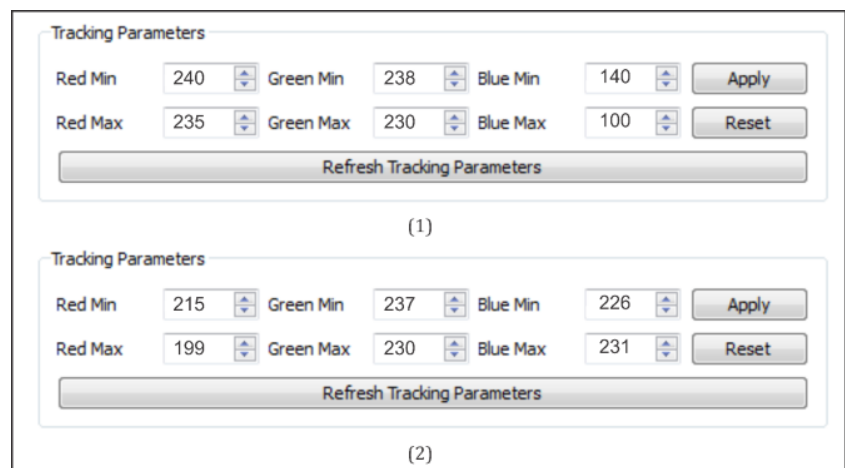

Gambar 10. (1) parameter RGB gawang; (2) parameter RGB Garis Lapangan

Dari hasil proses pengambilan sampel warna untuk proses pelacakan objek didapatkan beberapa nilai parameter RGB pada masing masing objek bola, gawang, dan garis tepi lapangan seperti diperlihatkan pada Tabel 1, Tabel 2, dan Tabel 3.

Tabel 1. Nilai Parameter RGB untuk dapat melacak bola

\begin{tabular}{|l|l|l|}
\hline No & Parameter Pelacakan & Nilai RGB \\
\hline 1. & RED_MIN & 183 \\
\hline 2. & RED_MAX & 225 \\
\hline 3. & GREEN_MIN & 72 \\
\hline 4. & GREEN_MAX & 154 \\
\hline 5. & BLUE_MIN & 41 \\
\hline 6. & BLUE_MAX & 139 \\
\hline
\end{tabular}

Tabel 2. Nilai Parameter RGB untuk dapat melacak gawang

\begin{tabular}{|l|l|l|}
\hline No & Parameter Pelacakan & Nilai RGB \\
\hline 1. & RED_MIN & 201 \\
\hline 2. & RED_MAX & 226 \\
\hline 3. & GREEN_MIN & 212 \\
\hline 4. & GREEN_MAX & 229 \\
\hline 5. & BLUE_MIN & 117 \\
\hline 6. & BLUE_MAX & 149 \\
\hline
\end{tabular}

Tabel 3. Nilai Parameter RGB untuk dapat melacak garis tepi lapang

\begin{tabular}{|l|l|l|}
\hline No & Parameter Pelacakan & Nilai RGB \\
\hline 1. & RED_MIN & 195 \\
\hline 2. & RED_MAX & 215 \\
\hline 3. & GREEN_MIN & 230 \\
\hline 4. & GREEN_MAX & 237 \\
\hline 5. & BLUE_MIN & 231 \\
\hline 6. & BLUE_MAX & 220 \\
\hline
\end{tabular}

Dalam pengujian sistem, hasil pelacakan terhadap bola dianalisis dengan membandingkan tiga orientasi robot dengan bola masing-masing pada posisi $45^{\circ}, 90^{\circ}$, dan $135^{\circ}$ seperti diilustrasikan dalam Gambar 11-13. Hasil pengujian memperlihatkan bahwa robot dapat mengenali bola dengan waktu pelacakan berturut-turut sekitar 12,2; 12,6; dan 18,7 detik.

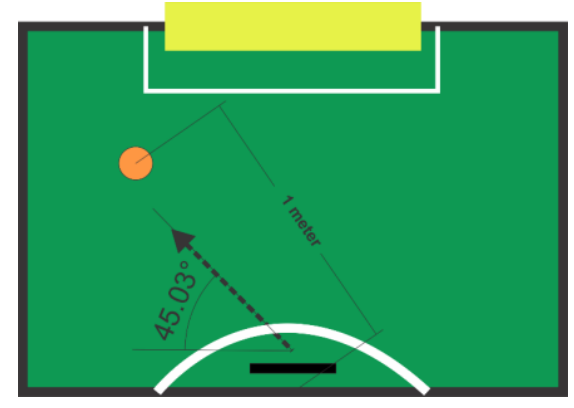

Gambar 11. Pelacakan bola pada orientasi $45^{\circ}$

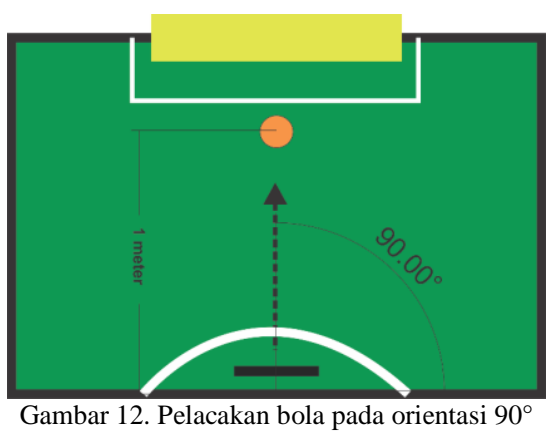




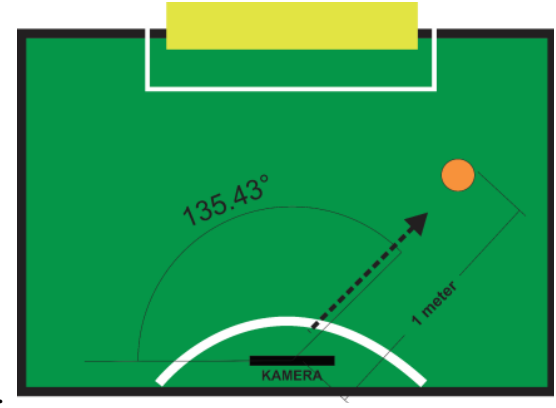

Gambar 13. Pelacakan bola pada orientasi $135^{\circ}$

Setelah mengenali bola, proses berikutnya adalah mengenali gawang dan melakukan proses membawa bola (dribbling) mendekati gawang yang snapshotnya diperlihatkan pada Gambar 14.

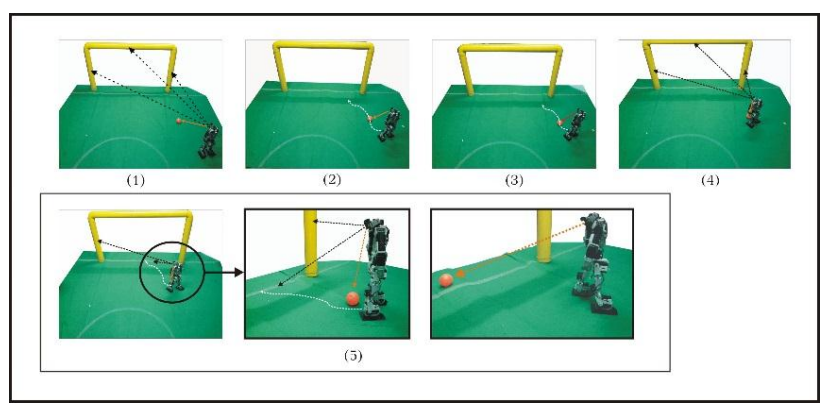

Gambar 14. Dribbling bola menuju gawang

\section{KESIMPULAN}

Makalah ini telah memaparkan tentang pemrosesan citra dari objek bola, gawang, dan tepi garis lapangan dalam sebuah robosoccer dengan menggunakan sensor kamera CMUcam4 yang sudah dilengkapi dengan pemroses citra didalamnya. Dari hasil pengujian memperlihatkan bahwa sensor kamera CMUcam4 dapat melacak warna bola, gawang, dan tepi garis lapangan dengan nilai parameter RGB yang sesuai dengan warna objeknya. Respon kamera CMUcam4 diamati relatif cepat dalam mengenali objek bola dengan waktu pelacakan objek bergantung kepada sudut orientasi robot dengan bolanya. Pengujian lain berkaitan dengan kemampuan mengenali gawang dan garis tepi lapangan menunjukkan bahwa robot dapat menggiring bola dan menendang bola ke arah gawang dalam kecepatan yang relatif konstan dan gerak yang mantap. Penelitian berikutnya yang dilakukan untuk menindaklanjuti hasil penelitian ini diarahkan kepada pemrosesan citra dengan algoritma tertentu yang menghasilkan akurasi dan komputasi yang efisien seperti yang diusulkan dalam [13] serta integrasi robosoccer dalam satu tim sehingga merepresentasikan suatu tim robot sepakbola.

\section{UCAPAN TERIMAKASIH}

Ucapan terima kasih disampaikan kepada LPPM Unjani yang telah mendanai sebagian penelitian yang dilakukan melalui skema Penelitian Kompetitif Tahun Anggaran 20152016. Terima kasih juga disampaikan kepada Agita Septian Putra yang telah membantu dalam implementasi program dan pengujian deteksi objek untuk robosoccer.

\section{DAFTAR PUSTAKA}

[1] L. Huang; Q. Song and N. Kasabov, "Evolving Connectionist System Based Role Allocation for Robotic Soccer", International Journal of Advanced Robotic Systems, Vol. 5, No. 1, 2008, pp. 59-62.

[2] FIRA - Federation of International Robot-soccer Association, http://www.fira.net/contents/sub01/sub01_2.asp, diakses tanggal 1 Maret 2015 pukul 11.00 .

[3] H. Zhang, H. Lu, P. Dong, D. Xiong, and Z. Zheng, “A Novel Generic Ball Recognition Algorithm Based on Omnidirectional Vision for Soccer Robots", International Journal of Advanced Robotic Systems, Vol.10, No. 388, 2013, pp. 1-12.

[4] A. Rahman dan N. S. Widodo, "Colored Ball Position Tracking Method for Goalkeeper Humanoid Robot Soccer", TELKOMNIKA, Vol. 11, No.1, March 2013, pp. 11-16.

[5] H. Lu, H. Zhang, S. Yang and Z. Zheng, "Vision-Based Ball Recognition for Soccer Robots without Color Classification", International Conference on Information and Automation, 22-24 June 2009, Macau, pp.916-921.

[6] C.L. Hwang, N. W. Lu, T.C. Hsu, and C.H. Huang, "Penalty Kick of a Humanoid Robot by a Neural-Network-Based Active Embedded Vision System", SICE Annual Conference 2010, August 18-21, 2010, The Grand Hotel, Taipei, Taiwan, 2291-2299.

[7] V. Bečanović, R. Hosseiny, and G. Indiveri, "Robot Soccer Using Optical Analog VLSI Sensors", International Journal of Robotics and Automation, Vol. 19, No. 4, 2004, pp. 213-221.

[8] R. Dodds, L. Iocchi, P. Guerrero, and J.R. Solar, "Benchmarks for Robotic Soccer Vision", dalam RoboCup 2011: Robot Soccer World Cup XV, Lecture Notes in Computer Science, Vol. 7416, 2012, pp 427 439.

[9] A. Treptow, A. Masselli and A. Zell, "Real-Time Object Tracking for Soccer-Robots without Color Information", Robotics and Autonomous Systems, Vol. 48, Issue 1, 31 August 2004, Pages 41-48.

[10] C. Siedentop, M. Schwarz, and S. Pfulb, "Introduction of Image Processing to Robocup Junior", dalam Robocup 2008 : Robot Soccer World Cup XII, Lecture Notes in Artificial Intelligences, Vol. 5399, 2009, pp. 308-317.

[11] http://www.cmucam.org, diakses tanggal 17 Maret 2015 pukul 19.00

[12] A. Goode, A. Rowe, and K. Agyeman, "Color Tracking Explanation", http://www.cmucam.org/projects/cmucam4/wiki/Colortracking_Explanation, diakses tanggal 20 Oktober 2014 pukul 21.00

[13] S.Y. Chiang, X. Guo, H.W. Hu, "Real-time Self Localization of Omni Vision Robot by Pattern Match System", International Conference on Advanced Robotics and Intelligent Systems (ARIS), 2014, 6-8 June 2014, Taipei, pp. 46-50. 